\title{
ADVANCED PROCESSING STEPS FOR HIGH EFFICIENCY SOLAR CELLS BASED ON EFG MATERIAL
}

\author{
J. Junge ${ }^{1}$, M. Kaes ${ }^{1,5}$, D. Groetschel ${ }^{1}$, A. Zuschlag ${ }^{1}$, S. Seren ${ }^{1}$, G. Hahn ${ }^{1,2}$, A. Metz ${ }^{3}$, \\ B. T. Chan $^{4}$, J. John ${ }^{4}$, G. Beaucarne ${ }^{4}$ \\ ${ }^{1}$ University of Konstanz, Department of Physics, P.O.Box X916, 78457 Konstanz, Germany \\ ${ }^{2}$ also with Fraunhofer Institute for Solar Energy Systems (ISE), Heidenhofstr. 2, 79110 Freiburg, Germany \\ ${ }^{3}$ SCHOTT Solar GmbH, Carl-Zeiss-Str. 4, 63755 Alzenau, Germany \\ ${ }^{4}$ IMEC, Kapeldreef 75, B-3001 Leuven, Belgium, ${ }^{5}$ now with Berlin Solar GmBH, Magnusstr.11, 12489 Berlin, Germany
}

\begin{abstract}
In the past few years the quality of Edge-defined Film-fed Growth (EFG) material has strongly improved and can now compete with most standard multicrystalline materials. The maximum conversion efficiency of solar cells based on high quality EFG material is at the moment mostly limited by the applied solar cell processing steps. The state-of-the-art high efficiency process at the University of Konstanz (UKN) in combination with some additional processing steps is presented. The latter include hydrogen passivation of bulk defects, texturisation of the front surface by remote $\mathrm{SF}_{6}$ plasma (most samples shown here were textured at IMEC), surface passivation using a silicon oxide / silicon nitride stack and the application of Laser Fired Contacts (LFC). Single additional processing steps are investigated as well as various combinations of additional processing steps.
\end{abstract}

\section{INTRODUCTION}

This paper focuses on high efficiency solar cell processing steps which were specially adapted for the processing of Edge-defined Film-fed Growth (EFG) silicon wafers. Due to its unique fabrication method [1] standard photolithography based processing has to be adapted for EFG-material. Below we want to concentrate on the following processing steps: bulk passivation (including firing of PECVD silicon nitride and remote hydrogen plasma), plasma texturing of the wafer front side, surfacepassivation via silicon oxide / silicon nitride stack and Laser Fired Contacts (LFC). Efficiencies of $18.2 \%$ on EFG (independently confirmed by the ISE CalLab) have been reached by applying some of the adapted process steps mentioned above [2].

\section{CELL PROCESS}

The photolithography based cell process at UKN (Figure 1) can easily be adapted to investigate the influence of single processing steps as well as the effect of a combination of processing steps. The first step is a surface damage etch (chemical polishing etch based on $\mathrm{HNO}_{3}, \mathrm{HF}$ and $\mathrm{CH}_{3} \mathrm{COOH}$ ). For lowering the reflection a plasma texturing step can be implemented. Emitter diffusion is carried out in a conventional $\mathrm{POCl}_{3}$ open tube diffusion furnace followed by an optional oxidation ( 10$15 \mathrm{~nm} \mathrm{SiO}$ ) for better front surface passivation before silicon nitride deposition by PECVD (reflection minimum at $540 \mathrm{~nm}$ - optimized for a second antireflection layer). An aluminium back surface field (AI-BSF) is formed by screen printing and firing.

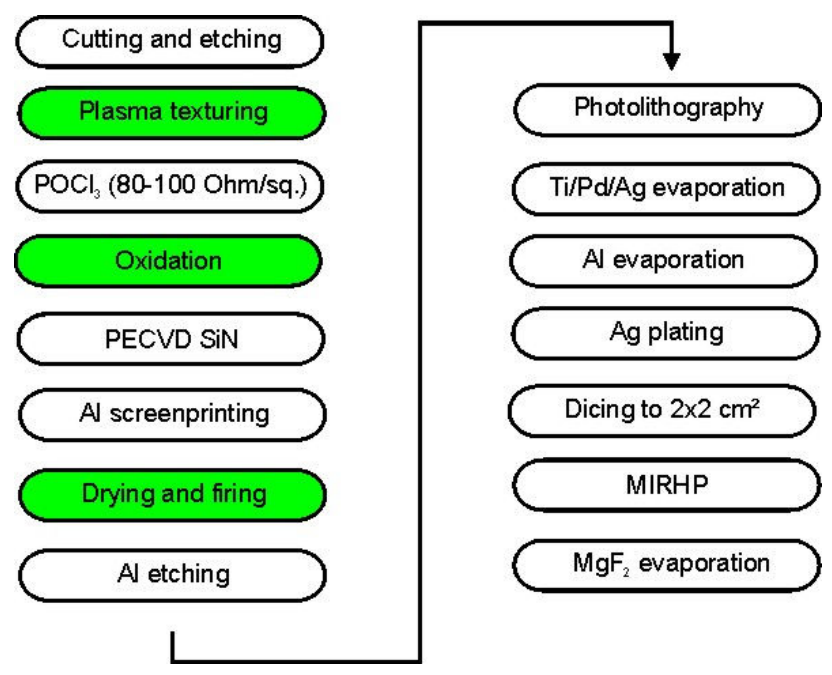

Figure 1: Photolithography based cell process at UKN. Investigated process steps for front side and bulk improvement are highlighted in green.

After Al etching, metallization is carried out using photolithography together with evaporation of contacts for front and rear side, followed by silver plating. Finally the $2 \times 2 \mathrm{~cm}^{2}$ solar cells are cut out of the $5 \times 5 \mathrm{~cm}^{2}$ structure using a wafer dicing saw with subsequent contact sintering and hydrogenation by Microwave Induced Remote Hydrogen Plasma (MIRHP). On selected samples a second antireflection layer $\left(\mathrm{MgF}_{2}\right)$ is evaporated on top of the silicon nitride. 


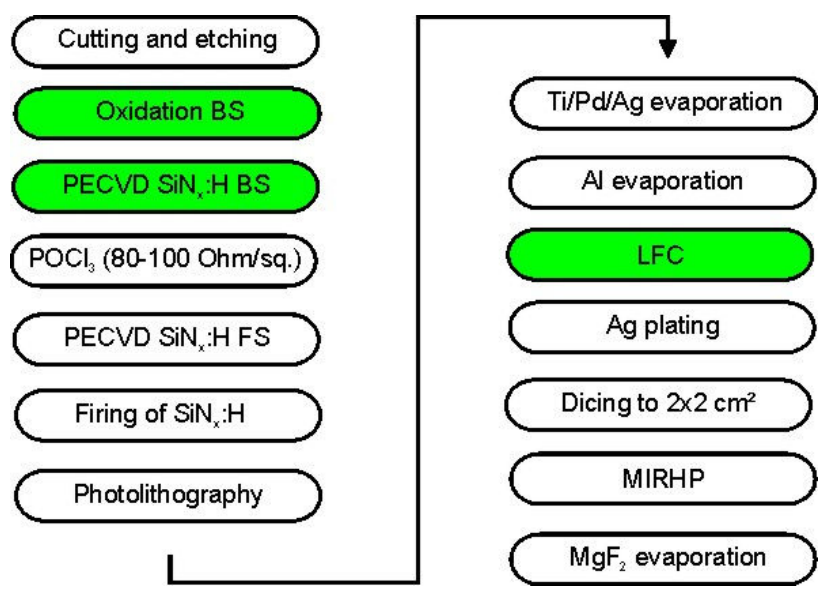

Figure 2: Changes in the standard cell process for the implementation of Laser Fired Contacts (BS = back side / $\mathrm{FS}=$ front side of the solar cell).

For solar cells with a dielectrical passivation on both sides an additional oxidation and PECVD silicon nitride deposition before the emitter diffusion is necessary. This replaces the Al-BSF screen printing process. The electrical contact for the rear side is formed via LFC (Figure 2).

\section{PLASMA TEXTURING}

Compared to the fabrication of standard multicrystalline silicon wafers, the production of EFG wafers does not induce any saw damage on the wafer surface. Thus most acidic texture solutions are not directly applicable. Plasma texturing in contrast does not rely on an existing saw damage. Recent results led to a very encouraging conversion efficiency of $17.8 \%$ on floatzone reference material with only a single anti-reflection coating and in combination with LFC even $18.5 \%$ (Table I). The process is currently optimized for EFG material.

Table I: IV-data of the best plasma textured solar cells with and without laser fired contacts before deposition of a second antirefection coating.

\begin{tabular}{|c|c|c|c|c|}
\hline Material & $\begin{array}{c}\mathbf{F F} \\
{[\%]}\end{array}$ & $\begin{array}{c}\mathbf{J}_{\mathbf{s c}} \\
{\left[\mathbf{m A} / \mathbf{c m}^{\mathbf{2}}\right]}\end{array}$ & $\begin{array}{c}\mathbf{V}_{\text {oc }} \\
{[\mathbf{m V}]}\end{array}$ & $\begin{array}{c}\boldsymbol{\eta} \\
{[\%]}\end{array}$ \\
\hline FZ & 80.5 & 35.0 & 630 & 17.8 \\
\hline FZ (LFC) & 77.7 & 36.2 & 658 & 18.5 \\
\hline EFG & 79.3 & 32.8 & 596 & 15.5 \\
\hline EFG (LFC) & 76.5 & 33.8 & 617 & 15.9 \\
\hline
\end{tabular}

Up to now plasma texturing is not yet established on an industrial scale. This is partially due to a significantly reduced blue response and to a somewhat reduced $V_{o c}$ which was observed in the past on plasma textured solar cells with a highly doped emitter [3]. The texturisation process applied at IMEC shows only a small reduction of the blue response on the lowly doped (80-100 $\Omega /$ sq.) emitter from UKN (Figure 3) [2]. Open circuit voltages up to $658 \mathrm{mV}$ on floatzone references have been achieved so far (Table I).

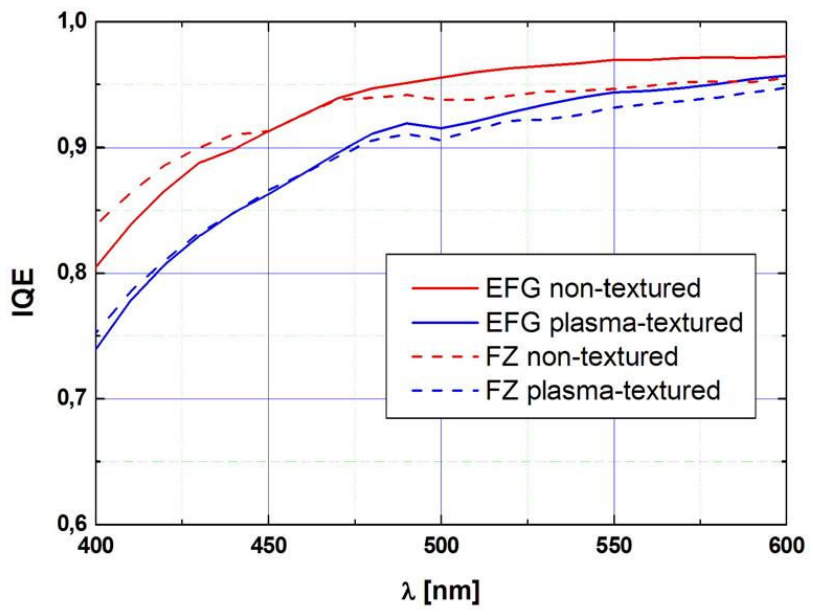

Figure 3: Blue response of plasma-textured solar cells compared to non-textured cells from EFG and floatzone material respectively.

\section{SURFACE PASSIVATION}

The commonly applied front surface passivation with a PECVD-deposited silicon nitride layer can be significantly enhanced introducing a thin thermal silicon oxide layer between the emitter surface and the silicon nitride $\left(\mathrm{SiO}_{2} / \mathrm{SiN}_{\mathrm{x}}\right.$ stack). Up to now an overall efficiency of $18.2 \%$ on EFG material has been achieved with the $\mathrm{SiO}_{2} / \mathrm{SiN}_{\mathrm{x}}$-stack on the front side. This value equals the record efficiency for EFG material reported in [4].

However, a combination of front surface passivation and plasma texturing has not been successful up to now.

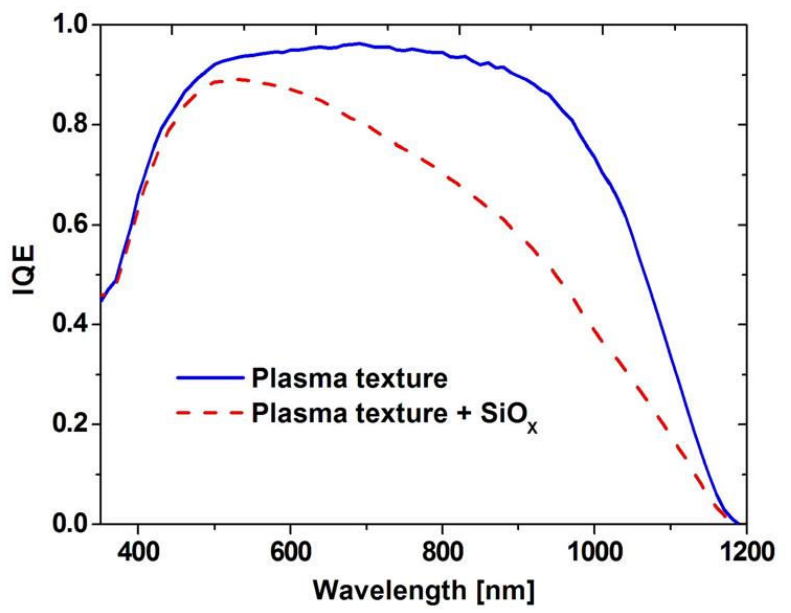

Figure 4: IQE of neighboring textured EFG solar cells, one with an additional $\mathrm{SiO}_{2}$ on the front surface. 
A cell process including these two additional processing steps resulted in a significantly reduced spectral response in the long wavelength regime (Figure 4).

A possible explanation for this behavior is that detrimental residuals from the plasma texturing are present on the surface, and are driven into the wafer bulk during the high temperature dry oxidation at about $900^{\circ} \mathrm{C}$. Another explanation might be crystalline defects which are generated due to stress release during the oxidation of the rough surface [5].

A current issue is the thickness reduction of EFG wafers. Recombination activity on the rear surface gains increasing influence on the cell parameters for thinner wafers. Consequently the improvement of the rear surface passivation is a major task. Therefore a direct comparison between 8 EFG solar cells, four with an Al-BSF and four with Laser Fired Contacts, fabricated from two neighboring $5 \times 5 \mathrm{~cm}^{2}$ wafers (about $200 \mu \mathrm{m}$ thick) was carried out (Table II). Both wafers were also plasma textured on the front side.

Table II: Comparison of neighboring EFG solar cells with Al-BSF or dielectrical rear surface passivation and LFC (mean values of the four solar cells).

\begin{tabular}{|c|c|c|c|c|}
\hline Rear side & $\begin{array}{c}\mathbf{F F} \\
{[\mathbf{\%}]}\end{array}$ & $\begin{array}{c}\mathbf{J}_{\mathbf{s c}} \\
{\left[\mathbf{m A} / \mathbf{c m}^{\mathbf{2}} \mathbf{]}\right.}\end{array}$ & $\begin{array}{c}\mathbf{V}_{\text {oc }} \\
{[\mathbf{m V} \mathbf{]}}\end{array}$ & $\begin{array}{c}\boldsymbol{\eta} \\
{[\%]}\end{array}$ \\
\hline Al-BSF & 78.7 & 31.1 & 581 & 14.2 \\
\hline LFC & 75.3 & 33.3 & 609 & 15.3 \\
\hline
\end{tabular}

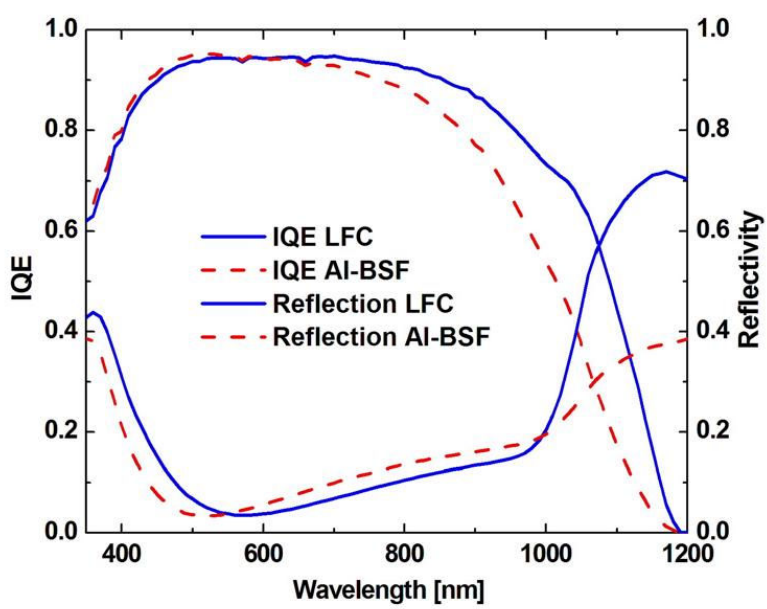

Figure 5: IQE and reflection measurements on two adjacent EFG solar cells. One with Al-BSF and one with dielectrical rear side and LFC.

The increased $V_{o c}$ and $J_{s c}$ values for the LFC-cells are attributed to the better back surface passivation. The lower average fill factor is due to a not yet optimized pitch for the Laser Fired Contacts which increases the series resistance $R_{s}$. Most remarkable is the strong increase in overall efficiency despite the rather limited quality of the material used for this comparison. Spectral response measurements on two adjacent solar cells confirm the results shown above (Figure 5). The better long wavelength IQE of the dielectrically passivated solar cell can be attributed to the better passivation quality and to the better reflectivity of the evaporated Aluminum of the rear side contact which reflects a large amount of notabsorbed light back into the cell.

\section{BULK PASSIVATION}

The performance of EFG solar cells strongly depends on an effective bulk defect passivation with hydrogen [6]. To investigate the specific influence of the defect passivation in the material bulk, special samples were prepared on adjacent wafers (Figure 7 and 8). Particular attention was paid to have continuous grains through the whole $20 \mathrm{~cm}$ of investigated area. At first the samples were prepared according to the process shown in Figure 6.

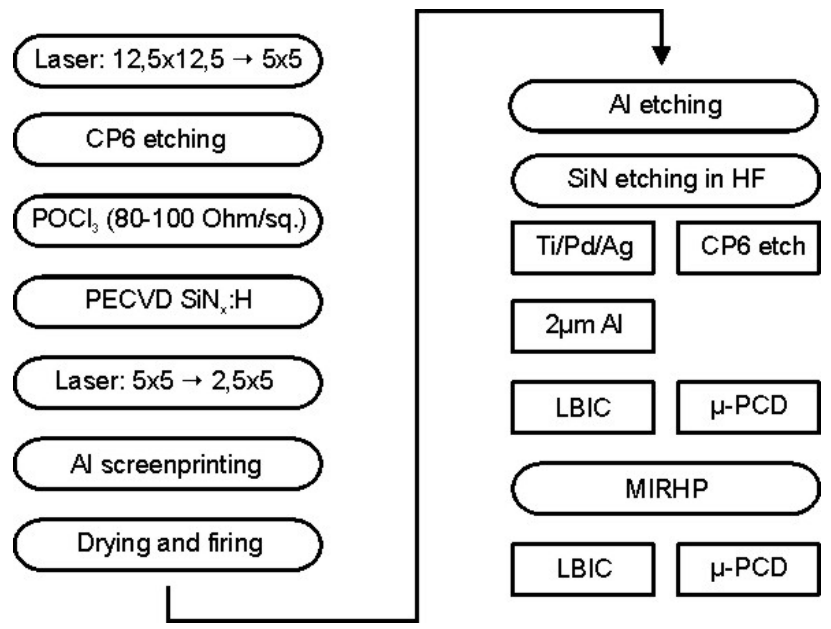

Figure 6: Process for the simplified fabrication of solar cells and lifetime samples. The split up in processing and characterization is shown in the right column (squared fields).

After the deposition of the silicon nitride the samples were fired with varying peak temperature set points $\left(700^{\circ} \mathrm{C}\right.$ to $\left.900^{\circ} \mathrm{C}\right)$ in a conventional belt furnace. Up to this point, solar cells and lifetime samples were processed in parallel. To simplify the further processing, the solar cells were prepared without a photolithography step. The front grid was evaporated through a shadow mask (after the removal of the silicon nitride layer). For the lifetime samples the emitter was removed using an etching solution similar to $\mathrm{CP} 6$.

The so prepared solar cells were then characterized spatially resolved via Light Beam Induced Current measurements (LBIC). The results (Figure 7, upper half) suggest that higher peak-firing-temperatures for the PECVD silicon nitride layer significantly increase the minority carrier diffusion length in the bulk. 


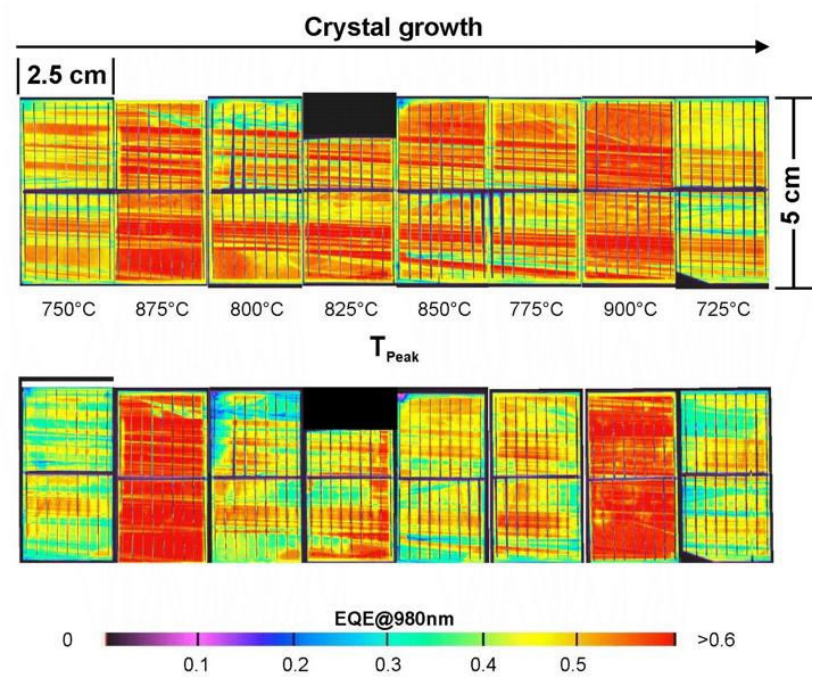

Figure 7: LBIC-results from adjacent cells with $\mathrm{SiN}_{\mathrm{x}}$ fired at different temperatures before (upper half) and after (lower half) an additional MIRHP-passivation step.

A subsequent MIRHP passivation step (Figure 7, lower half) even increases the beneficial effect for the samples that were fired at the highest temperatures $\left(875^{\circ} \mathrm{C}\right.$ and $\left.900^{\circ} \mathrm{C}\right)$.

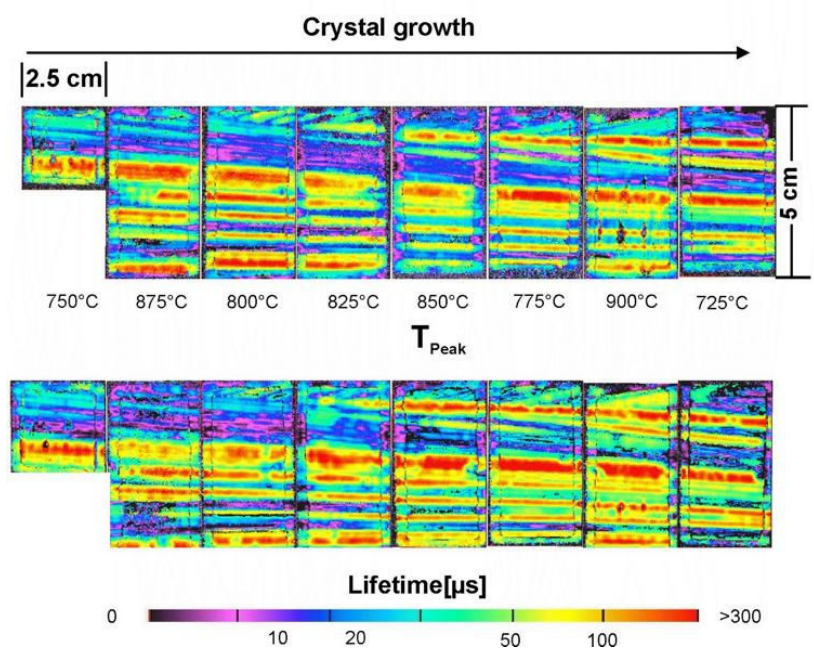

Figure 8: $\mu \mathrm{PCD}$-measurements from adjacent wafers with $\mathrm{SiN}_{\mathrm{x}}$ fired at different temperatures before (upper half) and after (lower half) an additional MIRHP passivation step.

The lifetime samples processed in parallel show no influence neither from the variation of the peak-firing temperature nor from the subsequent MIRHP passivation step (Figure 8 ). This inconsistent behavior could be either explained by a different surface passivation quality of the Al-BSF or by a change of diffusion constant of the material caused by the different peak-firing temperatures. Further investigations are in progress.

\section{SUMMARY}

As the quality of EFG material gets comparable to standard mc material, the maximum efficiency that can be achieved on best quality material is mostly limited by the applied cell processing steps. In this contribution we present new approaches to optimize the current photolithography based high efficiency cell process. Many single processing steps have proven to enhance the material quality by means of defect passivation and to enhance the solar cell efficiency by lowering reflection and surface recombination velocities. Efficiencies as high as the best so far reported of $18.2 \%$ [4] on EFG have been reached. The challenging task of combining and finetuning these processing steps is on its way and first encouraging results were obtained.

\section{OUTLOOK}

By investigating the combination and crossinfluences of the processing steps discussed above we aim to enhance the record efficiency reached on EFG material further to close the currently persisting efficiency gap to standard block cast multicrystalline silicon solar cells by means of optimized hydrogenation and cell processing steps.

\section{ACKNOWLEDGEMENTS}

The underlying projects of parts of this report were supported with funding by the EC (SES6-CT-2003$502583)$ and by the BMU $(0327650 \mathrm{H})$. The content of this publication is the responsibility of the authors.

\section{REFERENCES}

[1] R.O. Bell, J.P Kalejs, "Growth of silicon sheets for photovoltaic applications", J. Mater. Res., 13, 1998, p. 2732-2738.

[2] M. Kaes, G. Hahn, A. Metz, G. Agostinelli, Y. Ma, J. Junge, A. Zuschlag, D. Groetschel, "Progress in High Efficiency Processing of EFG Silicon Solar Cells" $22^{\text {nd }} E C$ PVSEC, 2007, p. 897.

[3] H.F.W. Dekkers, G. Agostinelli, D. Dehertoghe, G. Beaucarne, "Improved Performances of mc-si Solar Cells by Isotropic Plasma Texturing", $19^{\text {th }}$ EC PVSEC, 2004, Paris, p.412.

[4] A. Rohatgi et al., "High-efficiency solar cells on edgedefined film-fed grown (18.2\%) and string ribbon (17.8\%) silicon by rapid thermal processing", Appl. Phys. Lett., 84(1), 2004, p. 145. 
[5] P.J. Cousins, J.E. Cotter, "Minimizing lifetime degradation associated with thermal oxidation of upright randomly textured silicon surface", Solar Energy Materials and Solar Cells, 90(2), 2006, p. 228.

[6] A. Rohatgi, D.S. Kim, V. Yelundur, K. Nakayashiki, A. Upadhyaya, M. Hilali, V. Meemongkolkiat, "RecordHigh-Efficiency Solar Cells on Multicrystalline Materials Through Understanding and Implementation of RTPenhanced $\mathrm{SiN}_{\mathrm{x}}$-induced Defect Hydrogenation", $14^{\text {th }}$ PVSEC, 2004, Bangkok, p.635. 